Original Article

\title{
ENTADA PHASEOLOIDES ATTENUATES SCOPOLAMINE INDUCED MEMORY IMPAIRMENT, NEURO-INFLAMMATION AND NEURO-DEGENERATION VIA BDNF/TRKB/NFKB P65 PATHWAY IN RADIAL ARM MAZE
}

\author{
CHANDANA CHOUDHURY BARUA ${ }^{\mathrm{a}^{*}}$, LIPIKA BURAGOHAIN ${ }^{\mathrm{a}}$, ARUNDHATI PURKAYASTHA ${ }^{\mathrm{b}}$, BEENITA SAIKIA ${ }^{\mathrm{a}}, \mathrm{K}$. \\ SURESH BABU', G. SWARNA KUMARI', ACHEENTA GOHAIN BARUA ${ }^{\mathrm{d}}$
}

\begin{abstract}
aDepartment of Pharmacology and Toxicology, College of Veterinary Science, Assam Agricultural University, Guwahati, Assam 781022, India, bDepartment of Animal Biotechnology, College of Veterinary Science, Assam Agricultural University, Guwahati, Assam 781022, India, cDivision of Natural Products Chemistry, CSIR-Indian Institute of Chemical Technology, Hyderabad 500007, India, dDepartment of Veterinary Public Health, College of Veterinary Science, Assam Agricultural University, Guwahati, Assam 781022, India
\end{abstract} Email: chanacin@gmail.com

Received: 23 May 2018 Revised and Accepted: 24 Jul 2018

\section{ABSTRACT}

Objective: The present study investigates the protective effects of crude extract from seeds of Entada phaseoloides and isolated compounds in enhancing cognition in Scopolamine induced learning and memory impairments in the radial arm maze model.

Methods: Two doses (100 and $200 \mathrm{mg} / \mathrm{kg}$ ) of the crude methanolic extract of Entada phaseoloides (MEEP) were evaluated for amnesic activity by Radial Arm Maze memory model. Scopolamine ( $0.4 \mathrm{mg} / \mathrm{kg}$ i. p.), an amnestic drug was used for impairing memory. Tacrine ( $3 \mathrm{mg} / \mathrm{kg}$, i. p.) was used as the standard drug. Animals were sacrificed to evaluate biochemical parameters viz. lipid peroxidase (LPO), nitrite oxide (NO), reduced glutathione (GSH), superoxide dismutase (SOD), catalase (CAT), cytokine levels by ELISA, Catecholamine levels by high performance liquid chromatography (HPLC), Caspase-3 activity by Fluorogenic assay, Gene (BDNF, TrkB, NF- $\mathrm{kB}$ p65, BAX) expression studies by Western Blotting and AChE, $\alpha 7 \mathrm{nAchR}$, Caspase-3, Nrf2 and HO-1 by Reverse Transcriptase Polymerase Chain Reaction.

Results: Treatment with MEEP significantly decreases escape latency and reference memory error (RME). MEEP treatment reversed the Scopolamine-induced hyperactivation of Acetylcholinesterase activity and overexpression of proteins NF- $\mathrm{B}$ p65 BAX and also Caspase-3 activity in the hippocampus of rats. The level of BDNF, TrkB and $\alpha 7 \mathrm{nAchR}$ were significantly up-regulated and AChE, Caspase-3, Nrf2, HO-1 were downregulated in the MEEP treated rat. The extract increased the activity of SOD, GSH, Catalase, 5-HT, NE, Dopamine and decreased the levels of LPO and NO in rat hippocampus. Different active components of the seeds have been isolated.

Conclusion: These results indicated that seeds of Entada phaseoloides might become a promising therapeutic agent for the treatment of cognitive dysfunction in addition to its already established medicinal properties.

Keywords: Acetylcholinesterase, Catecholamine, Cholinergic, Entada phaseoloides, Scopolamine

(c) 2018 The Authors. Published by Innovare Academic Sciences Pvt Ltd. This is an open access article under the CC BY license (http://creativecommons.org/licenses/by/4.0/] DOI: http://dx.doi.org/10.22159/ijpps.2018v10i9.27487

\section{INTRODUCTION}

Since long human progress is utilizing plant and plant-derived products as a source of medicine. As the plants possess powerful activity against several diseases, in the recent scientific developments, so many medicinal properties of such plants have been investigated throughout the world. It possesses another advantage like no side effects and economic plausibility [1]. In spite of rich biodiversity in India and the traditional knowledge available through Ayurveda, Unani and Homeopathy, the pharmacological misuse of these therapeutic plants has still been constrained. Though some of the plants have been extensively investigated, others await thorough investigation. Not only this, the scientific validation of the traditional value of the medicinal plants needs careful investigation [2].

Alzheimer's disease is one of most common neurodegenerative disorders and a major health issue in the aging population. Neurodegenerative disorders are clinically characterized by a progressive loss of cognitive abilities, which affects learning and memory dysfunction in daily activity. Learning is defined as the acquisition of information and skills, and subsequent retention of that information is called memory. Learning and memory are fundamental higher brain functions that allow the individual to adapt to the environment [3]. The major factor in Alzheimer's disease is due to the release of free radicals generated within the brain [4]. The pathogenesis of neurodegenerative disorders still remains uncertain. However, the deposition of neurofibrillary tangles and/or senile plaques, neuro-excitotoxicity and cholinergic dysfunction are known to be causative factors. The cholinergic system, including cholinergic neurons, neurotransmitters, and their specific receptors play a central role in the memory process (encoding, memory storage, and retrieval). As a neurotransmitter, acetylcholine obviously enhances long-term potentiation (LTP) in the basal forebrain and hippocampus. These cholinergic functions are mediated by neurotrophins such as brain-derived neurotrophic factor (BDNF) and nerve growth factor (NGF), which maintain neuronal plasticity and synaptogenesis. Acetyl cholinesterase inhibitors and the agents that modulate cholinergic dysfunction, such as donepezil, rivastigmine, galantamine, and tacrine, have been used to treat patients with amnesia-related disorders such as Alzheimer's disease. However, these agents are not curatives, but are used to delay the progression of the disease and ameliorate the pathognomonic symptoms. Meanwhile, several study groups have recently analyzed the memory enhancing activities of herb derived natural product.

Impairment of memory by anti-cholinergic actions of scopolamine (muscarinic receptor blocker) is a useful model for evaluating antiamnesic effects of drugs [5, 6]. Scopolamine causes oxidative stress in rats leading to cognitive impairment. We have selected this model as one of most suitable method to study dementia [7]. Although the fact, the free radicals increase oxidative stress in brain leading to memory impairment, but its exact mechanism is still not clear.

Entada phaseoloides (Linn.) Merr. (Family: Fabaceae) is a wellknown medicinal plant distributed throughout the sub-Himalayan 
tract (from Nepal eastwards ascending to $4,000 \mathrm{ft}$. in Sikkim, in Assam, Bihar and Orissa) and in the monsoon forest of Western and Eastern Ghats. It is also abundant in Andaman and Nicobar Islands. Almost all of the parts this plant is used in indigenous systems of medicine, the people in tropical and sub-tropical regions of countries made preparations for the treatment of a wide variety of illnesses, including hemorrhoids, stomachache, toothache, spasm, gastritis, and lymphadenitis [8]. A paste prepared from the seeds is applied locally for inflammatory glandular swellings. A glycoside of entagenic acid possesses anti-neoplastic activity [9]. Previous investigations on the chemical constituents of this plant have yielded saponins, flavonoids, and terpenoids [10-13]. Dawane et al. [14] studied the effect of two formulations of Entada phaseoloides seeds after topical application in 'monoiodoacetate-induced osteoarthritis' in rats, since arthritis is a very common clinical condition affecting both sexes and all ages.

It is believed by the natives of Africa, that few species available there, have potent memory enhancing ability, which even enable them to communicate with their ancestors if taken at bedtime. However, there are no scientific evidences/reports of such claim or belief. As part of our continuing studies, efforts were directed towards identification of acetylcholinesterase (AChE) activity inhibitory constituents from this Indian medicinal plant. An initial screening was conducted using Morris Water Maze in mice (communicated). Methanolic extract of seeds of Entada phaseoloides showed promising activity against Scopolamine induced dementia in mice. Bioactivity-guided phytochemical analysis of methanolic extract led to the isolation and identification of four compounds (1-4). In this paper, we have presented AChE inhibitory activity of the crude extract along with isolation and structure elucidation of the isolated constituents.

\section{MATERIALS AND METHODS}

\section{Drug and chemicals}

For this study, Scopolamine hydrobromide, Tacrine hydrochloride (9-Amino-1, 2, 3, 4-tetrahydro-acridine hydrochloride hydrate), Acetylthiocholine iodide, 5,5'-dithio-bis-nitrobenzoic acid (DTNB), Griess reagent, Dopamine hydrochloride, Serotonin hydrochloride and Tetramethylbenzidine (TMB) were obtained from SigmaAldrich, USA. Enzyme-linked immunosorbent assay (ELISA) Kit was procured from RayBio ${ }^{\circledR}$, USA, RIPA lysis buffer from Amresco, USA and Canada. All other chemicals and reagents used in the present work were of analytical grades.

\section{Animals studies}

Adult male Wistar rats (170-200 g) were procured from the Department of Pharmacology and Toxicology, College of Veterinary Science, Assam Agricultural University, Guwahati, Assam. They were housed in polypropylene cages, with clean bedding materials, safe drinking water, $12 \mathrm{~h}$ light-dark cycle, fed standard laboratory food and water was given ad libitum. All experiments were performed according to the current guidelines for the care of laboratory animals by IAEC (Approval No.770/ac/CPCSEA/FVSc, AAU/ IAEC/11-12/118); the effort was made to minimize the suffering of the experimental animals throughout the study.

\section{Plant collection and identification}

The dried seeds of Entada phaseoloides were collected from local market during the month of April-May, 2016 and identified by taxonomist Dr. Iswar Chandra Barua, Principal Scientist, Department of Agronomy, Assam Agricultural University, Jorhat, Assam and a voucher specimen was deposited and kept at the herbarium of the Department of Agronomy, Assam Agricultural University, Jorhat785013, Assam [AAU/EVM/NW-3].

\section{Preparation of methanolic extract}

After removing the kernel from the seeds, they were shade dried, powdered mechanically, weighed and stored in airtight container. Then, $250 \mathrm{~g}$ of powdered material was soaked in $1000 \mathrm{ml}$ methanol for $72 \mathrm{~h}$ in a beaker and mixture was stirred every $18 \mathrm{~h}$ using a sterile glass rod. Filtrate was obtained three times with the help of Whatman filter paper no.1 and the solvent was removed by a rotary evaporator (BUCHI, R-210, Labortechnik AG, Meierseggstrasse
Switzerland) under reduced pressure leaving a dark brown residue (MEEP). It was stored in an airtight container at $4{ }^{\circ} \mathrm{C}$ until use. The recovery percentage with respect to dry powder was found to be $26.52 \% \mathrm{w} / \mathrm{w}$.

\section{Acute toxicity studies}

The acute toxicity studies of methanolic extract of Entada phaseoloides were performed according to the organization of economic corporation development (OECD) Guidelines No.423 by using albino mice of either sex (20-30g). The extracts were administered orally at $2000 \mathrm{mg} / \mathrm{kg}$ to a group of mice $(\mathrm{n}=3)$ and the percentage mortality, if any, was recorded. The animals were kept under observation for next $14 \mathrm{~d}$ for mortality or gross abnormality with the given doses. Based on the acute toxicity study, 100 and 200 $\mathrm{mg} / \mathrm{kg}$ oral dose were selected for the present study.

\section{Study design}

The experimental rats were divided into 5 groups $(n=6$ in each group).

Group I: Normal control received only Saline,

Group II: Negative control, received scopolamine $0.4 \mathrm{mg} / \mathrm{kg}$, i.p.

Group III: Standard control, received Tacrine $3 \mathrm{mg} / \mathrm{kg}$, i.p. +scopolamine, $0.4 \mathrm{mg} / \mathrm{kg}$ i. $\mathrm{p}$.

Group IV: Methanolic extract of Entada phaseoloides $100 \mathrm{mg} / \mathrm{kg}$, p.o. +scopolamine $0.4 \mathrm{mg} / \mathrm{kg}$ i. $\mathrm{p}$.

Group V: Methanolic extract of Entada phaseoloides $200 \mathrm{mg} / \mathrm{kg} \mathrm{p}$. o.+scopolamine $0.4 \mathrm{mg} / \mathrm{kg}$ i. p.

\section{Behavioural studies}

\section{Radial arm maze}

For studying spatial working memory in rats, radial arm maze (RAM) experiment is carried out $[15,16]$. The first entry into never-baited arms was scored as a reference memory error (RME). The behavioural recording was done by Any Maze apparatus (Stoelting and Co., USA).

\section{Biochemical estimation}

Biochemical tests were done $24 \mathrm{~h}$ after the last behavioral test. The total protein was estimated by the method of Bradford et al. [17].

\section{Assessment of oxidative stress and antioxidant status}

The pro-oxidant markers i.e. lipid peroxidation (LPO) [18] and nitric oxide (NO) [19], antioxidant proteins i.e. reduced glutathione (GSH) [20], superoxide dismutase (SOD) [21], catalase (CAT) [22] were measured spectrophotometrically (MultiscanGo, Thermo Fisher) as per standard protocol.

\section{Estimation of $\boldsymbol{\beta}$-Amyloid ${ }_{1-42}$}

The level of $\beta$-amyloid - $_{-42}$ in the brain tissue was done by sandwich ELISA using rat $\beta$ amyloid $1-42$ (Bioassay Technology laboratory, Shanghai, China) kit.

\section{Estimation of inflammatory cytokines}

The levels of inflammatory cytokines (IL-1 $\beta$ and TNF- $\alpha$ ) in the brain tissue were estimated using commercially available cytokine ELISA kits (Ray Biotech, USA) according to the manufacturer's instructions.

Estimation of norepinephrine (NE), dopamine (DA) and serotonin (5-HT)

NE, DA, and 5-HT concentrations were simultaneously estimated in the hippocampus with slight modification [23] using highperformance liquid chromatography with an electrochemical detector (UHPLC, Thermo Scientific Dionex Ultimate 3000, USA and Coulochem III electrochemical detector, Acclaim ${ }^{\circledR} 120$ C18 Column $4.6 \times 250 \mathrm{~mm} 5 \mu \mathrm{m})$.

\section{Estimation of Caspase- 3 using a fluorogenic substrate}

Caspase3 activity was measured using specific substrate Ac-DEVDAMC (Sigma) in Fluoroskan Ascent (Thermo Scientific). 


\section{SDS-PAGE and Immunoblot analysis}

The expression of the TrkB, BDNF, NF- $\mathrm{BB}$ p65 and BAX proteins in the hippocampus was analyzed by Western Blotting using a Hoefer Midi Gel apparatus (Harvard Apparatus, Holliston, MA). Approximately, 30 $\mathrm{mg}$ tissue of the hippocampus was homogenized in $5 \mathrm{ml}$ of chilled lysis buffer (RIPA Buffer, Amresco, USA) and centrifuged $(23,000 \times \mathrm{g})$ for 20 min at $4{ }^{\circ} \mathrm{C}$. The protein concentration of the supernatants was quantified by Bradford reagent (Himedia) with Bovine serum albumin (BSA) as the standard. Samples with 50 $\mathrm{gg}$ of total protein were mixed with an equal volume of $2 \mathrm{X}$ Laemmli buffer, boiled for $5 \mathrm{~min}$ at $95{ }^{\circ} \mathrm{C}$ cooled, loaded and separated in $10 \%$ polyacrylamide gels containing sodium dodecyl sulfate (SDS). The separated proteins were transferred to PVDF membranes for immunoblot analysis. After blocking with 3\% Bovine serum albumin in $1 \mathrm{X}$ TBST for $1 \mathrm{~h}$ at room temperature, the membranes were incubated overnight at $4{ }^{\circ} \mathrm{C}$ with primary antibodies ( $\beta$-Actin, TrkB, BDNF, NF- $\mathrm{B}$ p65 and BAX) at a dilution of 1:500; Santa Cruz Biotechnology, Santa Cruz, CA. On the following day, they were washed with $1 \mathrm{X}$ TBST and incubated with respective secondary antibodies conjugated to Horseradish peroxidase (HRP) (Santa Cruz Biotechnology, Inc) for $1 \mathrm{~h}$ at a dilution of 1:5000. The bands were visualized using TMB Blotting solution available commercially. The band intensities were quantified using Image J software (NIH, Bethesda, MD, USA).

\section{Reverse transcriptase PCR (RT-PCR)}

AChE, $\alpha 7 n$ AchR, Caspase-3, Nrf2 and HO-1 mRNA expressions were studied in the hippocampus tissue of rat brain by reverse transcriptase polymerase chain reaction. RNA was isolated from the hippocampus using TRIzol (Ambion). The concentration and purity of RNA were determined spectrophotometrically using micro drop plate. Approximately $1 \mu \mathrm{g}$ of total RNA was reverse transcribed using RevertAid First Strand cDNA synthesis kit (Thermo Scientific). The resultant cDNA was amplified separately with specific primer for AChE, $\alpha 7 n$ AchR, Caspase-3, Nrf2, HO-1, and Gapdh using DreamTaq Green PCR Master mix (2X) (Thermo Scientific). The Polymerase Chain reaction mixture was amplified in a Thermal cycler consisting of $5 \mu \mathrm{l}$ of $2 \mathrm{X}$ PCR master mix, $0.5 \mu \mathrm{l}$ of forward and reverse primer $(10 \mathrm{pmol} / \mu \mathrm{l}), 1 \mu \mathrm{l}$ of template and nuclease-free water to a total volume of $10 \mu$. The primers used for amplification are shown in table 1 . All PCR samples were denatured at $95^{\circ} \mathrm{C}$ for 3 min before cycling and were extended for $10 \mathrm{~min}$ at $72{ }^{\circ} \mathrm{C}$ after cycling. The PCR assay using primers was performed for 35 cycles at $95^{\circ} \mathrm{C}$ for $30 \mathrm{~s}$, annealing temperature varies for different primers for $45 \mathrm{~s}$ (table 1 ) and $72{ }^{\circ} \mathrm{C}$ for $45 \mathrm{~s}$. The PCR products were detected by electrophoresis on a $2 \%$ agarose gel containing ethidium bromide and the densities of each band were analyzed by an image analyzer (Image J).

Table 1: Sequence of the primers used in RT-PCR analysis

\begin{tabular}{|c|c|c|c|}
\hline Gene & Primer sequence (Forward and reverse) & Product size (base pair) & Annealing temp $\left({ }^{\circ} \mathrm{C}\right)$ \\
\hline \multirow[t]{2}{*}{ AChE } & Forward 5'-GATCCCTCGCTGAACTACACC-3' & 331 & $60^{\circ} \mathrm{C}$ \\
\hline & Reverse5'-GGTTCTTCCAGTGCACCATGTAGGAG-3' & & \\
\hline \multirow[t]{2}{*}{ Nrf2 } & Forward 5'-GAGACGGCCATGACTGAT-3' & 196 & $58^{\circ} \mathrm{C}$ \\
\hline & Reverse 5'-GTGAGGGGATCGATGAGTAA-3' & & \\
\hline \multirow[t]{2}{*}{ HO-1 } & Forward 5'-AAGAGGCTAAGACCGCCTTC-3' & 262 & $60^{\circ} \mathrm{C}$ \\
\hline & Reverse 5'-GCATAAATTCCCACTGCCAC-3' & & \\
\hline \multirow[t]{2}{*}{ GAPDH } & Forward 5'-AGGTTGTCTCCTGTGACTTC-3' & 130 & $58^{\circ} \mathrm{C}$ \\
\hline & Reverse 5'-CTGTTGCTGTAGCCATATTC-3' & & \\
\hline \multirow[t]{2}{*}{ Caspase-3 } & Forward 5'-AATTCAAGGGACGGGTCATG-3' & 105 & $60^{\circ} \mathrm{C}$ \\
\hline & Reverse 5'-GCTTGTGCGCGTACAGTTTC-3' & & \\
\hline \multirow[t]{2}{*}{$\alpha 7 \mathrm{nAchR}$} & Forward 5'-GAGTCTGCAGGCAGCAAGAATAC-3' & 510 & $60^{\circ} \mathrm{C}$ \\
\hline & Reverse 5'-GTGGAACATGTCTGAGTACCCCG-3' & & \\
\hline
\end{tabular}

\section{Statistical analysis}

Results are expressed as mean \pm SEM. Statistical analysis was performed by one-way analysis of variance (ANOVA) followed by post hoc Tukey's multiple range tests, using Graph Pad Prism software version 5.0 (San Diego, CA, USA). Results were considered statistically significant when $\mathrm{p}<0.05$.

\section{RESULTS}

\section{Chemistry}

The fractionation and purification led to the isolation of 4 compounds in the crude methanolic extract from the seeds of Entada phaseoloides. The structures of isolates were established using IR, MS, 1D and 2D NMR spectroscopic techniques. After comparing their spectral data with those reported in the literature [24], they were identified as known compounds (fig. 1) and confirmed as Oleic acid (1), Entadamide A (2), Entadamide A-beta-D-glucopyranoside (3) and 1-0-protocatechuoyl- $\beta$-D-glucose (4). (fig. 1)

\section{Isolation of compounds from Entada phaseoloides}

The methanolic extract $(10 \mathrm{~g})$ was subjected to column chromatography (silica gel, 100-200 mesh, eluting with hexane/ EtOAc mixture of increasing polarity) to give 40 column fractions. Column fractions were analyzed by TLC (silica gel 60 F254, hexane: EtOAc, 60:40), and fractions with similar TLC patterns were combined to give five major fractions $\left(\mathrm{F}_{1}, \mathrm{~F}_{2}, \mathrm{~F}_{3}, \mathrm{~F}_{4}, \mathrm{~F}_{5}\right)$. Fractions $\mathrm{F} 4$ was subjected to repeated column chromatography eluting with EtoAc: hexane (19:81) to yield compound 1. Fraction $F_{3}$ was subjected to column chromatography(CC) on silica gel (100-200 mesh) using a hexane-EtOAc (10:0-6:4) to yield subfractions $B_{1}$ and Compound 2. Subfraction $B_{1}$ was then purified by preparative TLC with $\mathrm{CHCl}_{3}: \mathrm{MeOH}(90: 10)$ to get compound 3. Repeated purification of fraction $\mathrm{F}_{4}$ on silica gel (230-400 mesh) using $\mathrm{CHCl}_{3}: \mathrm{MeOH}$ (yu90:10) followed by Preparative HPLC, yielded compound 4.

\section{Spectral data for isolates}

Oleic acid (1): Light yellow oil, ${ }^{1} \mathrm{H}-\mathrm{NMR}\left(500 \mathrm{MHz}, \mathrm{CDCl}_{3}\right) \delta: 5.35$ $(2 \mathrm{H}, \mathrm{m}), 2.33(4 \mathrm{H}, \mathrm{m}), 2.01(4 \mathrm{H}, \mathrm{m}), 1.64(4 \mathrm{H}, \mathrm{m}), 1.37-1.22(\mathrm{H}, \mathrm{m})$, $0.88(3 \mathrm{H}, \mathrm{t}, J=7.1$ and $6.2 \mathrm{~Hz}) .{ }^{13} \mathrm{C}$ NMR $\left(\mathrm{CDCl}_{3}, 75 \mathrm{MHz}\right) \delta: 180.55$, $129.93,129.63,34.11,31.91,29.76,29.66,29.60,29.53,29.37,29.32$, $29.14,29.05,27.20,27.13,24.64,22.67,14.05$. HR-ESI-MS m/z: 305.2456 (Calcd for $\mathrm{C}_{18} \mathrm{H}_{24} \mathrm{O}_{2} \mathrm{Na}$ : 305.2451).

Entadamide A (2): White amorphous powder, ${ }^{1} \mathrm{H}-\mathrm{NMR}(500 \mathrm{MHz}$, $\left.\mathrm{CDCl}_{3}\right) \delta: 7.62(1 \mathrm{H}, \mathrm{d}, J=14.5 \mathrm{~Hz}), 6.44(1 \mathrm{H}, \mathrm{br} \mathrm{s}), 5.69(1 \mathrm{H}, \mathrm{d}, J=14.6$ $\mathrm{Hz}), 3.71(2 \mathrm{H}, \mathrm{m}), 3.46(2 \mathrm{H}, \mathrm{m}), 2.32(3 \mathrm{H}, \mathrm{s}) .{ }^{13} \mathrm{C} \mathrm{NMR}\left(\mathrm{CDCl}_{3}, 75 \mathrm{MHz}\right)$ $\delta: 165.80,143.67,115.31,62.46,42.49,14.60$. HR-ESI-MS m/z: 162.0589 (Calcd for $\mathrm{C}_{6} \mathrm{H}_{12} \mathrm{NO}_{2} \mathrm{~S}: 162.0583$ ).

Entadamide A-beta-D-glucopyranoside (3): White amorphous powder, ${ }^{1} \mathrm{H}-\mathrm{NMR}\left(500 \mathrm{MHz}, \mathrm{CD}_{3} \mathrm{OD}\right) \delta: 2.33(3 \mathrm{H}, \mathrm{s}), 3.27(1 \mathrm{H}, \mathrm{m})$, $3.29(1 \mathrm{H}, \mathrm{m}), 3.35(1 \mathrm{H}, \mathrm{m}), 3.37(1 \mathrm{H}, \mathrm{m}), 3.46(1 \mathrm{H}, \mathrm{m}), 3.72(2 \mathrm{H}, \mathrm{m})$ $3.90(1 \mathrm{H}, \mathrm{m}), 3.96(1 \mathrm{H}, \mathrm{m}), 3.99(1 \mathrm{H}, \mathrm{m}), 4.29(1 \mathrm{H}, \mathrm{d}, J=7.9 \mathrm{~Hz}), 5.85$ $(1 \mathrm{H}, \mathrm{d}, J=14.58 \mathrm{~Hz}), 7.59(1 \mathrm{H}, \mathrm{d}, J=14.58 \mathrm{~Hz}) \cdot{ }^{13} \mathrm{C}$ NMR $(75 \mathrm{MHz}$, $\left.\mathrm{CD}_{3} \mathrm{OD}\right): \delta 165.58,142.31,114.83,102.39,75.8,75.67,72.97,69.36$, 68.23, 60.74, 38.92, 13.4. HR-ESI-MS m/z: 346.0946 (Calcd for $\left.\mathrm{C}_{12} \mathrm{H}_{21} \mathrm{NO}_{7} \mathrm{~S}: 346.0931\right)$.

1-0-protocatechuoyl- $\beta$-D-glucose (4): Color less gummy, ${ }^{1} \mathrm{H}-\mathrm{NMR}$ $(500 \mathrm{MHz}$, DMSO-d 6$) \delta: 6.91(1 \mathrm{H}, \mathrm{d}, J=8.68 \mathrm{~Hz}), 6.59(1 \mathrm{H}, \mathrm{brs}), 6.48$ $(1 \mathrm{H}, \mathrm{dd}, J=8.6$ and 2.5$), 4.47(1 \mathrm{H}, \mathrm{d}, J=6.8), 3.69(1 \mathrm{H}, \mathrm{m}), 3.47(1 \mathrm{H}$, $\mathrm{m}), 3.37(1 \mathrm{H}, \mathrm{m}), 3.18(3 \mathrm{H}, \mathrm{m}) .{ }^{13} \mathrm{C}$ NMR $\left(75 \mathrm{MHz}, \mathrm{CD}_{3} \mathrm{OD}\right) \delta: 174.56$, $152.15,148.65,129.14,117.64,117.12,112.84,103.74,76.96,76.45$, $73.43,69.74,60.88$. 
<smiles>CCCCCCC=CCCCCCCCCCC(=O)O</smiles>

Oleic acid (1)<smiles>CS/C=C/C(=O)NCCO</smiles>

Entadamide A (2)<smiles>CS/C=C/C(=O)NCCOC1OC2C(O)OC1C(O)C(O)C2O</smiles>

Entadamide A-beta-D-glucopyranoside(3)<smiles>O=C(O[C@@H]1O[C@H](CO)[C@@H](O)[C@H](O)[C@H]1O)c1ccc(O)c(O)c1</smiles>

1-O-protocatechuoyl-ß-D-glucose(4)

Fig. 1: The structures of the isolates: oleic acid (1), Entadamide A (2), Entadamide A-beta-D-glucopyranoside (3), 1-0-protocatechuoyl- $\beta$ D-glucose (4)

Radial arm maze study

Effect of MEEP on escape latency and reference memory errors in rat

\section{Escape latency (Sec)}

In Radial Arm Maze, a significant decline in the escape latency $(36.03 \pm 2.4 \mathrm{~s})$ could be observed $(\mathrm{p}<0.001)$ in MEEP $(200 \mathrm{mg} / \mathrm{kg})$, followed by Tacrine and MEEP (100 mg/kg) treatment, when compared to Scopolamine treated group (143.0 $\pm 6.7 \mathrm{~s}$ ) (table 2).
Reference memory error

Numbers of error committed showed a decreasing trend $(\mathrm{p}<0.001)$ in MEEP ( $200 \mathrm{mg} / \mathrm{kg}$ ), i.e., $0.28 \pm 0.030 \mathrm{~s}$, followed by Tacrine and MEEP (100 mg/kg) when compared to Scopolamine treated $(2.187 \pm 0.199 \mathrm{~s})$ group (table 2$)$. The Scopolamine treated group significantly increased $(\mathrm{p}<0.001)$ reference memory error compared to the control group. Reference Memory Error was ameliorated by the treatment of MEEP showing its anti-amnesic activity.

Table 2: Effect of MEEP on escape latency and reference memory error in rat hippocampus with scopolamine-induced memory impairment in radial arm maze, values are expressed as mean \pm SEM $(n=6)$. Statistical significance was determined by one-way ANOVA followed by Tukey's post hoc test; $p<* * *, p<\# \# \#$ when compared to control and Scopolamine treated group respectively

\begin{tabular}{lll}
\hline Groups & Escape latency (s) & Reference memory error \\
\hline Vehicle Control & $53.92 \pm 1.20$ & $0.08 \pm 0.01$ \\
Scopolamine treated (0.4 mg/kg i. p.) & $143.0 \pm 6.71$ & $2.19 \pm 0.19$ \\
Tacrine (3 mg/kg i. p.)+Scop. & $60.28 \pm 0.22$ & $0.65 \pm 0.08$ \\
MEEP (100 mg/kg p. o.)+Scop. & $66.31 \pm 0.60$ & $1.32 \pm 0.03$ \\
MEEP (200 mg/kg p. o.)+Scop. & $36.03 \pm 2.41^{\# \# \#}$ & $0.28 \pm 0.03 \# \# \#$ \\
\hline
\end{tabular}

Effect of MEEP on brain Acetylcholinesterase (AChE) activity in rat

The AChE levels in the hippocampus of scopolamine treated rats elevated significantly $(\mathrm{p}<0.001)$, when compared to the control group. Whereas, MEEP treatment remarkably decreased the level of AChE activity compared with Scopolamine induced group $(\mathrm{p}<0.001$ at 100 and $200 \mathrm{mg} / \mathrm{kg}$ oral doses) (155.3 $\pm 2.02 \mathrm{nM} / \mathrm{min} / \mathrm{mg}$, $146.7 \pm 1.45 \mathrm{nM} / \mathrm{min} / \mathrm{mg}$ ) (fig. 2).

The standard drug, Tacrine also significantly reduced $(p<0.001)$ the AChE activity in the hippocampus.

\section{Effect of MEEP on antioxidants in rat}

Antioxidants enzymes, GSH, SOD and Catalase, showed a significant decline $(\mathrm{p}<0.001)$ in Scopolamine treated group when compared to control. Whereas, the levels were found to elevate significantly $(44.00 \pm 0.57 \mu \mathrm{g} / \mathrm{mg}, 2.77 \pm 0.01 \mathrm{U} / \mathrm{mg}, 32.06 \pm 0.67 \mathrm{nMol} / \mathrm{min} / \mathrm{mg}$ ) (p<0.001) in MEEP $200 \mathrm{mg} / \mathrm{kg}$, p. o. dose respectively (fig. 3C, 3D, 3E) treated group when compared to Scopolamine treated group. A complete reversal in LPO and NO levels could be observed in Tacrine, MEEP (100 and $200 \mathrm{mg} / \mathrm{kg}$ ) treated groups at significantly decreasing ( $37.00 \pm 1.73 \mathrm{nMol} / \mathrm{g}, 35.33 \pm 0.88 \mu \mathrm{g} / \mathrm{mg})(\mathrm{p}<0.001)$ (fig. $3 \mathrm{~A}, 3 \mathrm{~B}$ ) levels respectively, when compared to scopolamine treated group. These levels thus ascertained the antioxidant property of our plant.

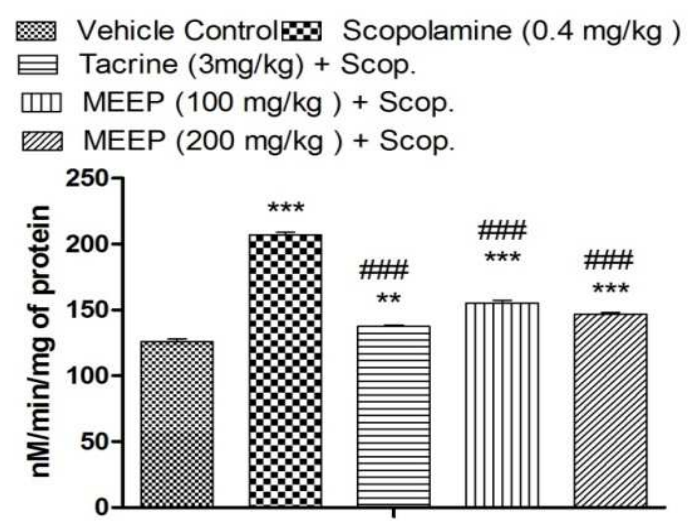

Acetylcholinesterase

Fig. 2: Effect of MEEP on acetylcholinesterase level in rat hippocampus with scopolamine-induced memory impairment in Radial arm maze. Values are expressed as mean $\pm \operatorname{SEM}(n=6)$.

Statistical significance was determined by one-way ANOVA

followed by tukey's post hoc test; $p<* * *, p<\# \# \#$ when compared to control and Scopolamine treated group respectively 
A

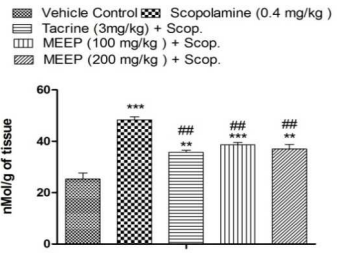

LPO
B

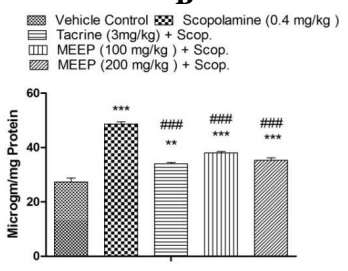

Nitrite Level
C

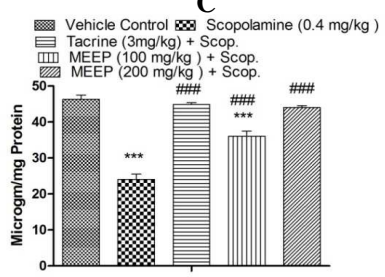

GSH
D

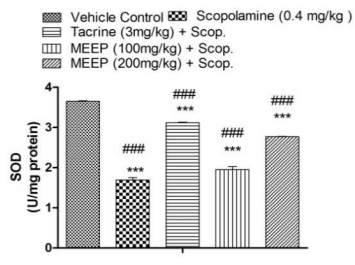

SOD
E

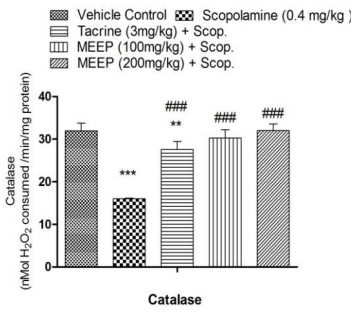

Fig. 3: Effect of MEEP in rat hippocampus with scopolamine-induced impaired memory in radial arm maze model on the levels of A) LPO B) NO C) GSH D) SOD and E) catalase, values are expressed as mean \pm SEM $(n=6)$, statistical significance was determined by one-way ANOVA followed by Tukey's post hoc test; ${ }^{* * *} \mathbf{p}<0.001$, \#\#\# $\mathbf{p}<0.001$, when compared to control and scopolamine, treated group respectively

Effect of MEEP on pro-inflammatory cytokines (IL-1 $\beta$ and TNF$\alpha)$ and $\beta$-amyloid in rat

Immunological assay by ELISA in the hippocampus of Scopolamine treated animals, revealed a significant $(p<0.001)$ elevation in the levels of pro-inflammatory cytokines viz. IL- $1 \beta(3018 \pm 89.63 \mathrm{pg} / \mathrm{ml})$ and TNF- $\alpha(5764 \pm 21.50 \mathrm{pg} / \mathrm{ml})$ in Scopolamine treated group, when compared to control, while a significant $(\mathrm{p}<0.001)$ decline in the cytokine levels could be observed MEEP $200 \mathrm{mg} / \mathrm{kg}$ treated animals $(1361 \pm 33.01 \mathrm{pg} / \mathrm{ml}, 2439 \pm 29.41 \mathrm{pg} / \mathrm{ml})$ when compared to Scopolamine treated group (fig. 4A, 4B).
A

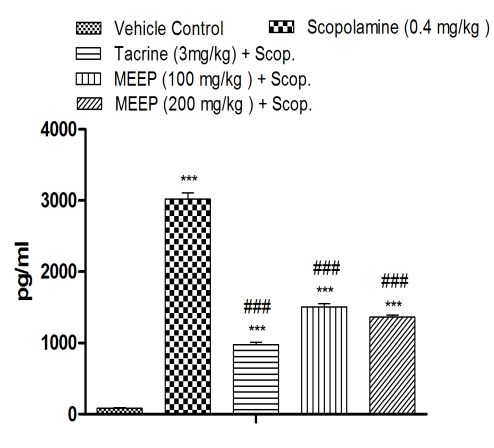

IL-1B
B

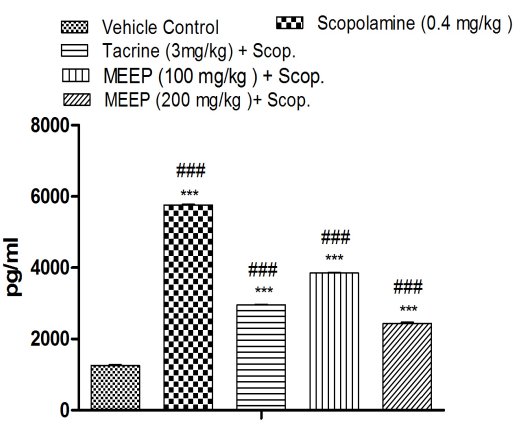

TNF-Alpha

C

W07 Scopolamine $(0.4 \mathrm{mg} / \mathrm{kg})$

풀 Vehicle Control

$\equiv$ Tacrine $(3 \mathrm{mg} / \mathrm{kg})+$ Scop.

III MEEP $(100 \mathrm{mg} / \mathrm{kg})+$ Scop.

MEE $\operatorname{MEEP}(200 \mathrm{mg} / \mathrm{kg})+$ Scop.

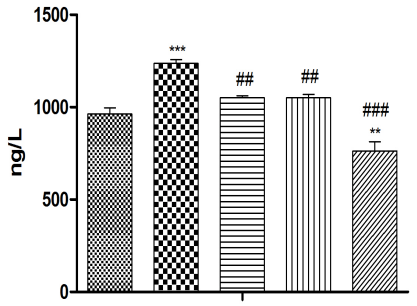

Beta-Amyloid

Fig. 4: Levels of pro-inflammatory cytokines A) IL-1 $\beta$, B) TNF- $\alpha$, C) $\beta$-amyloid in the rat hippocampus by ELISA in radial arm maze model. Values are expressed as mean \pm SEM $(n=6)$. Statistical significance was determined by one-way ANOVA followed by Tukey's post hoc test; ${ }^{* * *} \mathrm{p}<0.001,{ }^{\# \# \#} \mathrm{p}<0.001$, when compared to control and Scopolamine, treated group respectively 
Effects of MEEP on NE, DA and 5-HT levels in the hippocampus in Scopolamine induced rat.

Scopolamine significantly reduced NE $(96.96 \pm 6.2 \mathrm{ng} / \mathrm{gm})$, DA $(49.78 \pm 3.77 \mathrm{ng} / \mathrm{gm})$, and $5-\mathrm{HT}(67.16 \pm 3.35 \mathrm{ng} / \mathrm{gm})$ concentrations in the hippocampus compared to control animals. Administration of MEEP $100 \mathrm{mg} / \mathrm{kg}$ p. o. (fig. 5) was able to reverse the effects of scopolamine on reduced NE $(162.8 \pm 12.49 \mathrm{ng} / \mathrm{gm})$, DA $(310 \pm 14.16$ $\mathrm{ng} / \mathrm{gm})$ and 5 -HT $(90 \pm 5.62 \mathrm{ng} / \mathrm{gm})$ concentrations. Likewise, the standard drug Tacrine reversed the effects of scopolamine on NE, DA and 5-HT (fig. 5)

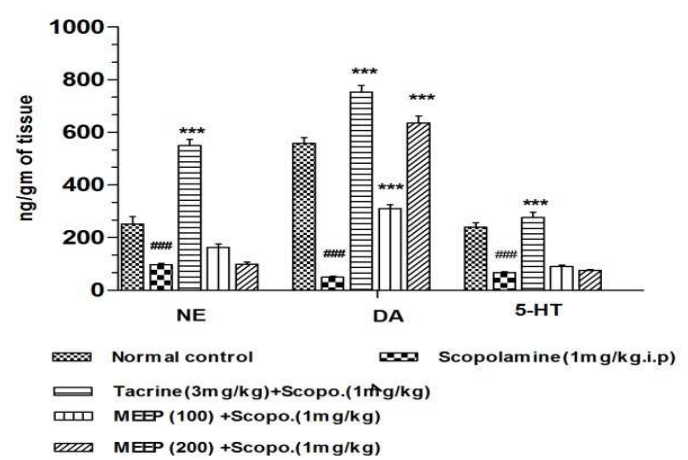

Fig.5: Effects of MEEP on NE, DA and 5-HT levels in rat hippocampus with Scopolamine induced memory loss. All values are mean $\pm S E M$. $\# p<0.05$ and $\# \# p<0.01$ versus control group and ${ }^{*} p<0.05$ and ${ }^{* *} p<0.01$ versus Scopolamine induced group

\section{Effect of MEEP on caspase-3 using a fluorogenic substrate}

Fluorogenic assay of Caspase- 3 revealed a significant decline in the levels in Tacrine $(\mathrm{p}<0.001)$ and MEEP $(200 \mathrm{mg} / \mathrm{kg})(0.0035 \pm 0.00$ $\mathrm{nMol} / \mathrm{ml} / \mathrm{min})(\mathrm{p}<0.05)$ (fig. 6), when compared to the scopolamine $0.0038 \pm 0.00 \mathrm{nMol} / \mathrm{ml} / \mathrm{min}$ ) treated group. Thus, confirming the anti-apoptotic activity similar to that of the standard drug (fig. 6)

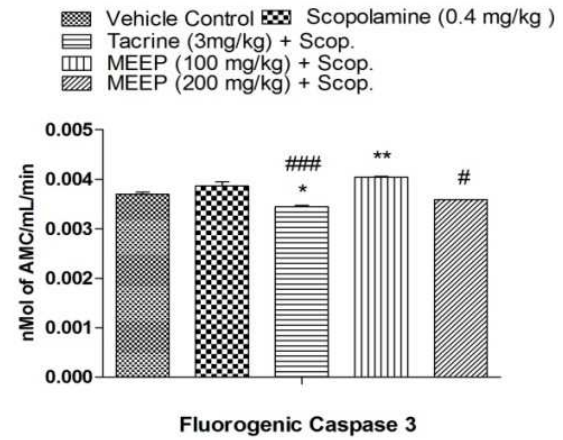

Fig. 6: Fluorescence-based caspase-3 activity assay showing its expression levels in rat hippocampus with scopolamineinduced impaired memory. Values are expressed as nMol of $\mathrm{AMC} / \mathrm{ml} / \mathrm{min}$ represented as mean $\pm \operatorname{SEM}(n=6)$. Statistical significance was determined by one-way ANOVA followed by Tukey's post hoc test; ${ }^{* * *} \mathbf{p}<\mathbf{0 . 0 0 1}$ when compared to control and $\# \# \#<<0.001$ when compared to Scopolamine group

\section{Immunoblotting analysis of NF- $\mathrm{KB}$ p65, BAX, BDNF and TrkB}

The Immunoblotting assay of NF- $\mathrm{BB}$ p65, BAX, BDNF and TrkB showed significant down-regulation of BDNF $(p<0.01)$ and $\operatorname{TrkB}$ $(p<0.001)$ protein in the hippocampal tissue of scopolamine-induced rats compared to control group. However, pre-treatment with MEEP significantly up-regulated BDNF (100 and $200 \mathrm{mg} / \mathrm{kg} ; \mathrm{p}<0.05$, $\mathrm{p}<0.01)$ and TrkB (100 and $200 \mathrm{mg} / \mathrm{kg} ; \mathrm{p}<0.01, \mathrm{p}<0.001)$ protein expression in the hippocampal tissues of rat similar to Tacrine $(\mathrm{p}<0.01, \mathrm{p}<0.001$ in BDNF and TrkB), as compared to scopolamine treated rats. On the other hand, significant $(p<0.001)$ up-regulation in the expression of BAX and NF- $\mathrm{KB}$ p65 in the hippocampal tissue of scopolamine-induced rats compared to the control group were observed. Pre-treatment with MEEP significantly downregulated BAX ( 100 and $200 \mathrm{mg} / \mathrm{kg}$; $<<0.001, \mathrm{p}<0.01$ ) and NF- $\mathrm{kB}$ p65 (100 and $200 \mathrm{mg} / \mathrm{kg}$; $<<0.05, \mathrm{p}<0.001$ ) protein in the hippocampal tissues of rat similar to that of standard drug Tacrine $(p<0.01, p<0.001)$, when compared with scopolamine alone treated group (fig. 7).
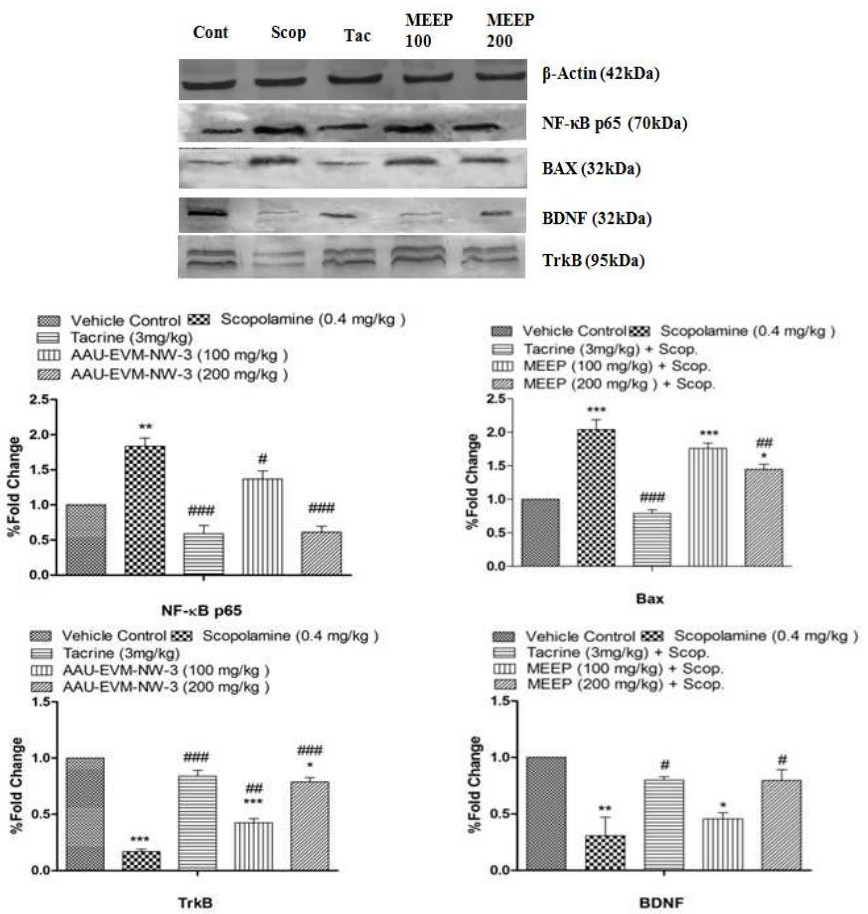

Fig. 7: Quantitative expression of NF-кB p65, BAX, BDNF and TrkB genes by western blotting in different treatment groups viz. Control, Scopolamine, Tacrine, MEEP $(100 \mathrm{mg} / \mathrm{kg})$, MEEP $(200 \mathrm{mg} / \mathrm{kg})$ in rat hippocampus with Scopolamine induced memory loss. Values are expressed as percent fold change represented as mean $\pm \operatorname{SEM}(n=6)$. Statistical significance was determined by one-way ANOVA followed by Tukey post hoc test; ${ }^{* * *} \mathbf{p}<0.001$ when compared to control, ${ }^{\# \# \#} \mathbf{p}<0.001$ when compared to Scopolamine group 


\section{RT-PCR analysis of AChE, $\alpha 7 \mathrm{nAChR}$, Caspase-3, Nrf2 and HO-1 genes}

The RT-PCR analysis of AChE, $\alpha 7 \mathrm{nAChR}$, Caspase-3, Nrf2 and HO-1 gene expression are presented (fig. 8), the mRNA expression levels of AChE, $\alpha$ 7nAChR, Caspase-3, Nrf2 and HO-1 were significantly $(\mathrm{p}<0.001, \mathrm{p}<0.001, \mathrm{p}<0.001, \mathrm{p}<0.001$ and $\mathrm{p}<0.05)$ up-regulated in the hippocampal tissues of scopolamine-induced rats, respectively, compared to the control group. However, pre-treatment with MEEP significantly down-regulated the mRNA expression of AChE (MEEP $200 \mathrm{mg} / \mathrm{kg} ; \mathrm{p}<0.001$ ), Nrf2 (MEEP 100 and $200 \mathrm{mg} / \mathrm{kg} ; \mathrm{p}<0.001$ ),
Caspase-3 (MEEP 100 and $200 \mathrm{mg} / \mathrm{kg}$; $\mathrm{p}<0.001$ ) and HO-1 (MEEP 100 and $200 \mathrm{mg} / \mathrm{kg} ; \mathrm{p}<0.001$ ) genes' expression in the hippocampal tissues of rat, similar to that of standard drug, Tacrine as compared to the scopolamine treated rats. On the other hand, mRNA expression levels of $\alpha 7 \mathrm{nAChR}$ were significantly $(\mathrm{p}<0.01)$ downregulated in the hippocampal tissues of scopolamine treated rats compared to the control group. Pre-treatment with MEEP (100 and $200 \mathrm{mg} / \mathrm{kg}$ ) significantly upregulated the mRNA expression of $\alpha 7 \mathrm{nAChR}$ $(\mathrm{p}<0.001, \mathrm{p}<0.001)$ gene in the hippocampal tissues of rat similar to Tacrine, when compared with scopolamine treated group (fig. 8).

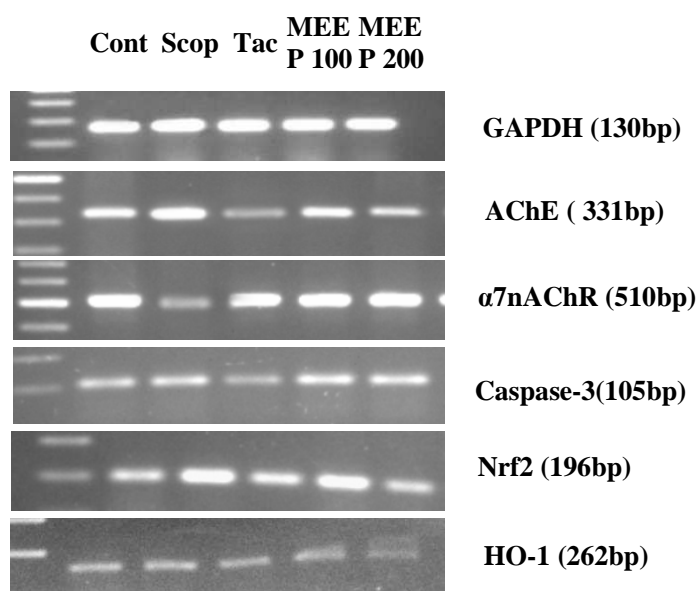

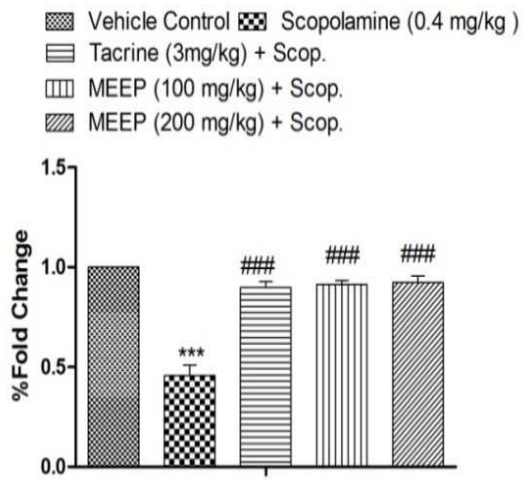

Alpha-7-nAChR

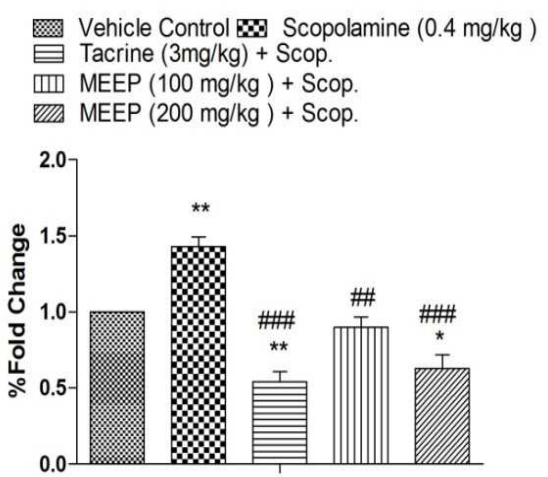

AChE

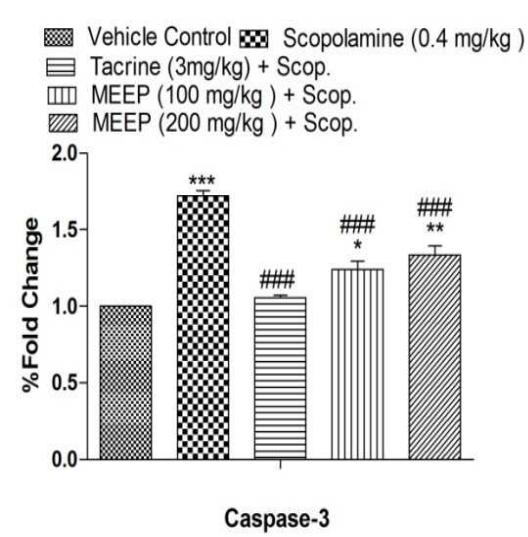

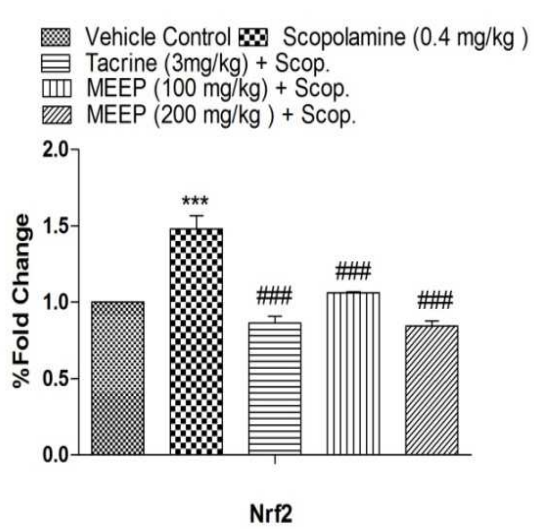

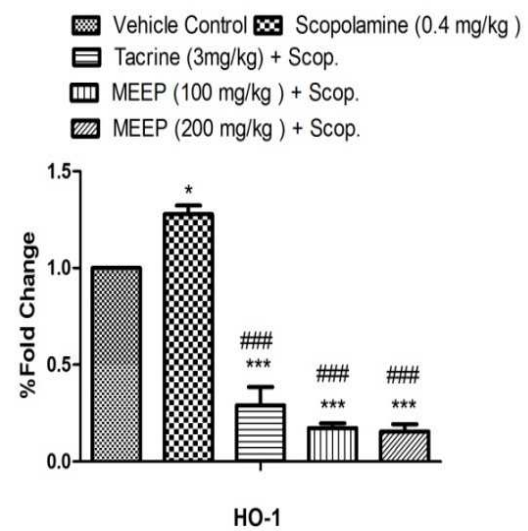

Fig. 8: Quantitative expression of Alpha-7-nAChR, AChE, Caspase-3, Nrf2 and HO-1 gene by Reverse Transcriptase PCR in different treatment groups viz. Control, Scopolamine, Tacrine, MEEP $(100 \mathrm{mg} / \mathrm{kg})$, MEEP $(200 \mathrm{mg} / \mathrm{kg})$ in rat hippocampus with Scopolamine induced memory loss. Values are expressed as percent fold change, represented as mean \pm SEM $(n=6)$. Statistical significance was determined by one-way ANOVA followed by Tukey post hoc test; ${ }^{* * *} \mathbf{p}<0.001$ when compared to control, \#\#\#p $<0.001$, when compared to Scopolamine, treated group 


\section{DISCUSSION}

Among the neurodegenerative disorders, memory impairment is the most typical feature, which results from neuronal dysfunction and neuronal loss in the brain tissues, particularly the hippocampal region [25]. There is no effective way to cure the disorder or stop the neurodegenerative processes. Thus, research has been focused on discovering how to intercede neuro-degeneration of Alzheimer disease. Currently, ethnobotanical and traditional uses of natural compounds, especially of plant origin received much attention, as they are well tested for their efficacy which is believed to be safe. They clearly merit examination on present-day logical lines, for example, phytochemical examination, organic assessment on exploratory creature models, examination of the sub-atomic system of activities of detached phyto-standards and their clinical preliminaries. It is the best traditional approach looking for new lead atoms for the administration of different illnesses [26]. In our study, we examined the effects of Entada phaseoloides to alleviate memory deficits in radial arm maze model in rats. Pre-treatment with MEEP $(200 \mathrm{mg} / \mathrm{kg}$, p. o.) demonstrated a significant reduction of escape latency and a significant elevation of reference memory error in Radial Arm maze. The results showed that MEEP $(200 \mathrm{mg} / \mathrm{kg})$ improved the cognitive performance in scopolamine-induced cognitive impairment in rats.

The boost in cholinergic activity and inhibition of AChE enzyme is a promising therapy to treat a cognitive defect in Alzheimer's disease [27]. Administration of MEEP at $200 \mathrm{mg} / \mathrm{kg}$ oral dose significantly reversed the elevated AChE level. Thus, the results suggest that cognition enhancing the property of MEEP could be due to inhibition of AChE enzyme.

Free radicals are compound or substances that can exist independently with at least one unpaired electron. The proliferation of free radicals can achieve a large number of responses and subsequently may cause extensive tissue injury. Antioxidants may offer resistance against oxidative stress by scavenging the free radicals, inhibiting lipid peroxidation etc. [28]. The scopolamine induced memory deficit model exhibits prominent oxidative stress and memory deficits, although the mechanism remains unclear [29, 30]. The hippocampus plays a crucial role in short and long-term memory and highly susceptible to oxidative stress [31]. Our results show that scopolamine induction increased the levels of LPO and NO, following administration of MEEP or Tacine, significant attenuation of their levels was visible.

To protect tissues against oxidative damage, cellular organisms maintain an antioxidant system containing enzymatic and nonenzymatic components. SOD and catalase play an important role in the detoxification of superoxide anion and hydrogen peroxide respectively and protect the cells against oxidative damage induced by free radicals [32]. Our study shows that scopolamine significantly decreased the antioxidant capacity of SOD, Catalase and GSH in the hippocampus of rat brain, whereas pretreatment with MEEP significantly ameliorated these level to restore neuronal plasticity and memory function.

Cognitive dysfunction is generally accompanied by elevated proinflammatory cytokines and inflammation mainly in the hippocampal region. ROS under oxidative stress may initiate and exaggerate the inflammatory response due to their capability to stimulate and regulate the inflammatory-signaling cascades genes like NF-kB p65 and pro-inflammatory cytokines [33]. Scopolamine-induced rats also showed increased NF-кB p65 activity, pro-inflammatory cytokines (TNF $\alpha$, IL-1 $\beta$ ), and due to increased oxidative stress. MEEP treatment led to a significant decrease in the NF- $\mathrm{kB}$ p65 activity and its downstream pro-inflammatory cytokines (TNF $\alpha$, IL-1 $\beta$ ).

Aggregation of $\beta$ amyloid protein in the brain tissue lead to cognition impairment which is characterized by plaque deposition in extracellular spaces, and $\beta$ amyloid ${ }_{1-42}$ is predominant in the brain. Pre-treatment with MEEP at the given dose resulted in a significant decrease in the amount of $\beta$ amyloid 1-42 $_{2}$ in the rat brain.

In stressful conditions, change in dopamine level is associated with a transient change in behavioral aberrations, memory, learning disorders [34]. Administration of MEEP increased dopamine concentration in the scopolamine-induced amnesic model in the hippocampus, following $14 \mathrm{~d}$ of pre-treatment, revealed in HPLC analysis. The extract might show cognition enhancement by increasing dopamine level, which is more prominent than other catecholamines, namely, NE or 5HT observed in our experiment.

In our phytochemical study, 4 compounds have been isolated and identified in the active compound. Oleic acid isolated from the seeds of Entada phaseoloides has many positive effects on health. Few reported its usefulness for proper brain function [35, 36]. Consumption of oleic acid replaces other omega fatty acids in cell membrane as it is less susceptible to oxidation damage. Oleic acid protects the cell membrane from free radical and other oxidative stressors [37]. E. phaseoloides could exert its effect due to its oleic acid component. Ikegami et al., 1989, reported that Entadamide A, has inhibitory activity on 5-Lipoxygenase pathway. Hence it might exert an anti-inflammatory effect.

In our study, scopolamine induced apoptotic neuronal cell death by decreasing anti-apoptotic signalling (Bcl-2) and increasing apoptotic signalling (BAX and Caspase-3 activity). Suuronen et al. [38] showed that Scopolamine-induced apoptosis in cultured neuronal cells might be due to an increase in oxidative stress. Preventive treatment with MEEP led to decreased oxidative stress resulting in an improvement in anti-apoptotic (Bcl2) expression and decreased pro-apoptotic (BAX and Caspase-3 activity) genes indicating neuro-protection.

BDNF could be a diagnostic biomarker in patients with early Alzheimer's disease and mild cognitive impairment [39]. In the present study, the MEEP treatment almost restored the levels of the BDNF proteins, and its receptor, TrkB in the hippocampus, considerably downregulated by scopolamine. We observed that hippocampal BDNF level was significantly suppressed in the scopolamine-treated animal as compared to normal control group. Our study showed an up-regulation in hippocampal BDNF expression in the groups treated with MEEP like Tacrine.

We examined the effects of MEEP on key modulators of the cholinergic system in the hippocampus. Hippocampal cholinergic dysfunction has been observed in neurodegenerative disorders with memory impairment, including Alzheimer's disease, in both clinical studies [40] and animal experiments [41 and 42]. The scopolamine injection interrupts the transmission of acetylcholine into the postsynaptic membrane, which sequentially enhances AChE activity to catalyse the hydrolysis of acetylcholine [43]. MEEP treatment attenuated the AChE activity and down-regulated the expression of the AChE, $\alpha 7 \mathrm{nAChR}$, Caspase-3, Nrf2, HO-1 mRNA. The inhibition of AChE activity enhances basal dendritic long-term potentiation (LTP) in the hippocampal CA1 (first region of the hippocampal circuit) area, and it is mediated by muscarinic M1 receptors [44]. To date, reversible cholinesterase inhibitors have been considered a promising strategy for the pharmacotherapy of mild to moderated Alzheimer's disease [45]. It could be possible that MEEP possesses cholinergic property, which we could see in isolated rat ileum (unpublished report).

Adult hippocampal neurogenesis plays an important role in memory formation. Therefore, impaired neurogenesis and neuronal integration are regarded as pathological features of neurodegenerative disorders [46]. As expected, the MEEP treatment notably reversed the scopolamine-induced inhibition of neurogenesis in the hippocampal region. This neurogenesis is known to depend on the activities of both neurotrophins and their receptors [47].

Taken together, this study for the first time showed that MEEP exerted anti-amnesic actions in scopolamine-induced amnesia. We have also investigated its effect on various models like Morris water maze, Barnes maze etc. in addition to in radial arm maze presented in this study. Its active compounds were also isolated by structural analysis; hence further study with the active compound may yield a new chemical entity.

In summary, the present investigation sheds light on the potent neuroprotective potential of Entada phaseoloides seeds in 
scopolamine-induced neurotoxicity. The effect is likely to result from the inhibition of Acetylcholinesterase enzyme activity, suppressing $\beta$-amyloid plaque formation, inhibition of oxido-nitrosative stress and pro-inflammatory cytokines elevation in the hippocampus. It also significantly ameliorated the cognitive dysfunction in scopolamine-treated animal's up-regulating the expression of BDNF gene in the hippocampus, which is the hallmark for depression and memory-related disorders.

\section{CONCLUSION}

It is presumed from the present study that MEEP may be used as a therapeutic agent in the treatment of cognitive dysfunctionassociated disorders such as Alzheimer's disease or any other neurodegenerative disorders. It will be interesting to study this plant to this direction for scientific validation. Hence, future research may be directed towards the use of pure/semi-pure compound isolated from the extract in clinical trials to evaluate its neuroprotective effect on human.

\section{ACKNOWLEDGMENT}

The authors grateful to ICAR, New Delhi, for providing necessary financial support to conduct this study in the "Outreach Project on Ethnoveterinary Medicine" grant no FPA 1-2/2009. JD (Res) dtd 16.11.2009. The authors also express their sincere thanks to the Director of Research (Vety), AAU, Khanapara for providing a facility for carrying out the work.

\section{AUTHORS CONTRIBUTIONS}

All the authors are equally contributed for this above research outcomes in the form of manuscript preparation by conducting research related to the animal work, acute toxicity, compilation, writing, copy editing of text etc.

\section{CONFLICT OF INTERESTS}

We declare that there is no conflict of interest

\section{REFERENCES}

1. Patil M. Quantification of phytochemical constituents and in vitro antioxidant activity in the leaves of Citrus medica. Int J Curr Pharm Res 2017;9:119-23.

2. Maurya SK, Singh AK, Seth A. Potential medicinal plants for Lymphatic filariasis: a review. J Crit Rev 2015;5:1-6.

3. Kothari S, Singhal T. Docosahexaenoic acid administration ameliorates scopolamine-induced memory impairment in mice. Asian J Pharm Clin Res 2018;11:349-52.

4. Ikeda Y, Long DM. The molecular basis of brain injury and brain edema the role of oxygen radicals. Neurosurgery 1990;27:1-11.

5. El-Sherbiny DA, Khalifa AE, Attia AS, Eldenshary EEDS. Hypericum perforatum extract demonstrates antioxidant properties against elevated rat brain oxidative status induced by an amnestic dose of scopolamine. Pharmacol Biochem Behav 2003;76:525-33.

6. Mishima K, Tsukikawa H, Miura I, Inada K, Abe K, Matsumoto Y, et al. Ameliorative effect of NC-1900, a new AVP4-9 analog, through vasopressin $\mathrm{V} 1 \mathrm{~A}$ receptor on scopolamine-induced impairments of spatial memory in the eight-arm radial maze. Neuropharmacology 2003;44:541-52.

7. Kang SY, Lee KY, Park MJ, Kim YC, Markelonis GJ, Oh TH, et al. Decursin from Angelica gigas mitigates amnesia induced by scopolamine in mice. Neurobiol Learn Mem 2003;79:11-8.

8. Mohan VR, Janardhanan K. Chemical and nutritional evaluation of raw seeds of the tribal pulses Parkia roxburghii G. Don. and Entada phaseoloides (L.) Merr. Int J Food Sci Nutr 1993;44:47-53.

9. Kumar A. Entada phaseoloides (Linn.) Merr. syn. E. scandens: A glycoside of entagenic acid possesses anti-neoplastic activity. Science 2.0; 2009.

10. Ramakrishna D, Pavan KK, Mukkanti K, Abedulla KK. Antiulcer activity of the seeds of Entada phaseoloides. Pharmacologyonline 2008;3:93-9.

11. Ikram M, Babar ZM, Islam AMT, Chowdhury MAU, Uddin ME, Islam MR, et al. Antidiabetic and hypolipidemic effects of the different fractions of methanolic extracts of Entada phaseoloides (L.) Merr. In alloxan-induced diabetic mice. Int J Pharm Sci Res 2011;2:3160-5.
12. Liu WC, Kugelman M, Wilson RA, Roa KV. A crystalline saponin with antitumor activity from Entada phaseoloides, The John L. Smith Memorial Cancer Res 1972;11:171-3.

13. Li K, Xing S, Wang M, Peng Y, Dong Y, Li X. Anticomplement and antimicrobial activities of flavonoids from Entada phaseoloides. Nat Prod Commun 2012; 7:867-71.

14. Dawane JS, Pandit V, Rajopadhye B, Karandikar M. The effect of two formulations of Entada phaseoloides seeds after topical application in 'monoiodoacetate-induced osteoarthritis' in rats. J Exp Integr Med 2013;3:37-41.

15. Esteban S, Garau C, Aparicio S, Moranta D, Barcelo P, Fiol MA. Chronic melatonin treatment and its precursor L-tryptophan improve the monoaminergic neurotransmission and related behaviour in the aged rat brain. J Pineal Res 2010a;48:170-7.

16. Esteban S, Garau C, Aparicio S, Moranta D, Barcelo P, Ramis M. Improving effects of long-term growth hormone treatment on monoaminergic neurotransmission and related behavioral tests in aged rats. Rejuvenation Res 2010b;13:707-16.

17. Bradford MM. A rapid and sensitive method for the quantisation of microgram quantities of protein utilizing the principle of protein-dye binding. Anal Biochem 1976;72:248-54.

18. Ohkawa H, Ohishi N, Yagi K. Assay for lipid peroxidation in animal tissues by the thiobarbituric acid reaction. Anal Biochem 1979;95:351-8.

19. Miranda KM, Espey MG, Wink DA. A rapid, simple spectrophotometric method for simultaneous detection of nitrate and nitrite. Nitric Oxide Biol Chem 2001;5:62-71.

20. Ellman GL. Tissue sulfhydryl groups. Agric Biochem Biophys 1959;82:70-7.

21. Marklund S, Marklund G. Involvement of the superoxide anion radical in the auto-oxidation of pyrogallol and a convenient assay for superoxide dismutase. Eur J Biochem 1974;47:469-74.

22. Sinha AK. Colorimetric assay of catalase. Analytical Biochem 1972;47:389-94.

23. Sheikh MA, Noah MN, Tsuha K, Oomori T. Occurrence of tributyltin compounds and characteristics of heavy metals. Int J Environ Sci Tech 2007;4:49-59.

24. Yuqiong D, Haiming Shi, Haisha Y, Yunhua P, Mengyue W, Xiaobo L. Antioxidant phenolic compounds from the stems of Entada phaseoloides. Chem Biodivers 2012;9:68-79.

25. Scheff SW, Price DA, Schmitt FA, Mufson EJ. Hippocampal synaptic loss in early Alzheimer's disease and mild cognitive impairment. Neurobiol Aging 2006;27:1372-84.

26. Handral HK, Pandith A, Shruthi SD. A review on Murraya koenigii: Multipotential medicinal plant. Asian J Pharm Clin Res 2012;5:5-14.

27. Sutar RC, Kalaichelvan VK. Evaluation of antioxidant activity of leaf extracts of Holoptelea integrifolia (Roxb) planch. Int J Appl Pharma 2014;6:6-8.

28. Agrawal R, Tyagi E, Saxena G, Nath C. Cholinergic influence on memory stages: A study on scopolamine amnesic mice. Indian J Pharmacol 2009;41:192-6.

29. Giridharan VV, Thandavarayan RA, Sato S, Ko KM, Konishi T. Prevention of scopolamine-induced memory deficits by schisandrin B, an antioxidant lignan from Schisandra chinensis in mice. Free Radical Res 2011;45:950-8.

30. Harrison FE, Hosseini AH, Dawes SM, Weaver S, May JM. Ascorbic acid attenuates scopolamine-induced spatial learning deficits in the water maze. Behav Brain Res 2009;205:550-8.

31. Mattson MP, Pedersen WA, Duan W, Culmsee C, Camandola S. Cellular and molecular mechanisms underlying perturbed energy metabolism and neuronal degeneration in Alzheimer's and Parkinson's diseases. Ann N Y Acad Sci 1999;893:154-75.

32. Liu RH, Runyon RS, Wang YC, Oliver SG, Fan TP, Zhang WD. Deciphering ancient combinatorial formulas: the shexiang baoxin pill. Science 2015;347:540-2.

33. Rosales Corral S, Reiter RJ, Tan D, Ortiz GG, Lopez Armas G. Functional aspects of redox control during neuroinflammation. Antioxid Redox Signal 2010;13:193-247.

34. Muralidharan P, Balamurugan G, Venu B. Cerebroprotective effect of Glycyrrhiza glabra Linn. root extract on hypoxic rats. Bangladesh J Pharmacol 2009;4:60-4.

35. Hamazaki K, Hamazaki T, Inadera H. Fatty acid composition in the postmortem amygdala of patients with schizophrenia, bipolar disorder, and major depressive disorder. J Psychiatr Res 2012;46:1024-8. 
36. Ochoa JJ, Pamplona R, Ramirez Tortosa MC, Granados Principal S, Perez Lopez P, Naudi A, et al. Age-related changes in brain mitochondrial DNA deletion and oxidative stress are differentially modulated by dietary fat type and coenzyme Q1. Free Radical Biol Med 2011;50:1053-64.

37. Haug A, Hostmark AT, Harstad OM. Bovine milk in human nutrition-a review. Lipids Health Disease 2007;6:25.

38. Suuronen T, Kolehmainen P, Salminen A. Protective effect of $L$ Deprenyl against apoptosis induced by okadaic acid in cultured neuronal cells. Biochem Pharmacol 2000;59:1589-95.

39. O'Bryant SE, Hobson V, Hall JR, Waring SC, Chan W, Massman P, et al. Brain-derived neurotrophic factor levels in Alzheimer's disease. J Alzheimers Dis 2009;17:337-41.

40. Garibotto V, Tettamanti M, Marcone A, Florea I, Panzacchi A, Moresco R, et al. Cholinergic activity correlates with reserve proxies in Alzheimer's disease. Neurobiol Aging 2013;34:2694.

41. Craig LA, Hong NS, McDonald RJ. Revisiting the cholinergic hypothesis in the development of Alzheimer's disease. Neurosci Biobehav Rev 2011;35:1397-409.
42. Cutuli D, Foti F, Mandolesi L, De Bartolo P, Gelfo F, Federico F, et al. Cognitive performances of cholinergically depleted rats following chronic donepezil administration. J Alzheimers Dis 2009;17:161-76.

43. Tota S, Hanif K, Kamat PK, Najmi AK, Nath C. Role of central angiotensin receptors in scopolamine-induced impairment in memory, cerebral blood flow, and cholinergic function. Psychopharmacol (Berl) 2012;222:185-202.

44. Doralp S, Leung LS. Cholinergic modulation of hippocampal CA1 basal-dendritic long-term potentiation. Neurobiol Learn Mem 2008;90:382-8.

45. Colovic MB, Krstic DZ, Lazarevic-Pasti TD, Bondzic AM, Vasic VM. Acetylcholinesterase inhibitors: pharmacology and toxicology. Curr Neuropharmacol 2013;11:315-35.

46. Brinton RD, Wang JM. Therapeutic potential of neurogenesis for prevention and recovery from Alzheimer's disease: Allopregnanolone as a proof of concept neurogenic agent. Curr Alzheimer Res 2006;3:185-90.

47. Hagg T. From neurotransmitters to neurotrophic factors to neurogenesis. Neuroscientist 2009;15:20-7. 